\title{
TUJUAN DAN MANFAAT DOKUMENTASI KEPERAWATAN DALAM PROSES ASUHAN KEPERAWATAN
}

\author{
Natalia Cristianti P Marbun
}

\author{
Email : christiantinatalia72@gmail.com
}

\section{LATAR BELAKANG}

Keperawatan sebagai profesi merupakan salah satu pekerjaan dimana dalam menentukan tindakan didasari pada ilmu pengetahuan serta memiliki kertampilan yang jelas dalam keahliannya, selain itu sebagai profesi keperawatan mempunyai otonomi dalam kewenangan dan tanggung jawab dalam tindakan serta adanya kode etik dalam bekerjanya kemudian juga berorientasi pada pelayanan dengan melalui pemberian asuhan keperawatan kepada individu, kelompok atau masyarakat (Hidayat, 2011). Praktik keperawatan di masa mendatang harus dapat berorientasi pada klien. Hal ini berdasarkan tren perubahan dan persaingan yang semakin ketat saat ini. Perawat Indonesia di masa depan harus dapat memberikan asuhan keperawatan dengan pendekatan proses keperawatan yang berkembang, agar tingkat profesionalitas keperawatan itu semakin nampak.

Sejak zaman Florence Nightingale, perawat telah menganggap dokumentasi sebagai bagian yang vital dari praktik professional. Pada tulisan awalnya Nightingale menggambarkan tentang perlunya perawat untuk mencatat "penggunaan yang tepat dari udara segar, cahaya, kehangatan, kebersihan, serta pemilihan dan pemberian diet yang tepat," dengan tujuan mengumpulkan ,menyimpan dan mendapatkan kembali data untuk menatalaksanakan pasien secara cerdas. Asuhan keperawatan merupakan proses atau rangkaian kegiatan pada praktik keperawatan yang diberikan secara langsung kepada klien pasien di berbagai tatanan pelayanan kesehatan. Dilaksanakan berdasarkan kaidah-kaidah keperawatan sebagai suatu profesi yang berdasarkan ilmu dan kiat keperawatan, bersifat humanistik , dan berdasarkan pada kebutuhan objektif klien untuk mengatasi masalah yang dihadapi klien. Salah satu bagian yang terpenting dari asuhan keperawatan ialah dokumentasi. Dokumentasi merupakan tanggung jawab dan tugas perawat setelah melakukan intervensi keperawatan. Tetapi akhir-akhir ini tanggung jawab perawat 
terhadap dokumentasi sudah berubah. Oleh karena perubahan tersebut, maka perawat perlu menyusun suatu dokumentasi yang efisien dan lebih bermakna dalam pencatatannya dan penyimpanannya (Nursalam, 2008).

Dokumentasi keperawatan merupakan suatu yang mutlak harus ada untuk perkembangan keperawatan khususnya proses profesionalisasi keperawatan serta mempertahankan keperawatan sebagai suatu profesi yang luhur dan terpandang di masyarakat. Dokumentasi keperawatan dalam bentuk dokumen asuhan keperawatan merupakan salah satu alat pembuktian atas tindakan perawat selama menjalankan tugas pelayanan keperawatan. Dokumentasi yang baik mencerminkan kualitas perawatan dan yang membuktikan pertanggung jawaban setiap anggota tim perawatan dalam memberikan asuhan keperawatan pada klien.

\section{METODE}

Metode yang digunakan dalam jurnal dengan bahan kajian Tujuan dan Manfaat Dokumentasi Keperawatan dalam Proses Asuhan Keperawatan Di Rumah Sakit ini menggunakan metode tersearch atau pengumpulan data dengan menggunakan beberapa literature review seperti teks buku,referensi jurnal,ebook dengan menganalisis dan membaca setiap sumber literature berkenaan dengan topik materi yang sedang dibahas untuk mendapatkan berbagai informasi yang lengkap dan akurat dengan cara menyimpulkannya dari literature review yang ada. Sumbersumber yang dibaca dan dicari penulis juga berkenaan dengan materi permasalahan yang akan dibahas oleh penulis agar sistematis dan berkaitan sehingga mempermudah pemahaman pembaca.

\section{HASIL}

Undang-Undang RI Nomor 44 Tahun 2009 tentang Rumah Sakit Pasal 52 menyatakan bahwa setiap rumah sakit wajib melakukan pencatatan dan pelaporan semua penyelenggaraan kegiatan rumah sakit dalam bentuk sistim informasi manajemen berupa pencatatan, penyimpanan, pelaporan dan pemusnahan dalam waktu tertentu sesuai peraturan perundang-undangan.Rumah sakit dalam pengelolaannya mempunyai pilar yang saling terkait satu sama lain yaitu: 
administrasi, manajemen berupa perencanaan setiap kegiatan, disiplin dari pelakunya, leadership dan kepemimpinan diri. Teori menyatakan "tulis apa yang ingin dilakukan, lakukan apa yang telah ditulis dan tulis apa yang telah dilakukan". Pelayanan yang diselenggarakan rumah sakit ada dua jenis yaitu pelayanan kesehatan dan administratif. Pelayanan administratif salah satunya adalah dokumentasi keperawatan yang berisi catatan keperawatan sebagai bukti pelaksanaan proses keperawatan dan catatan tanggapan/respon klien terhadap tindakan medis dan tindakan keperawatan yang telah dilaksanakan.

Penerapan kompetensi proses keperawatan dapat dinilai dari pencatatan dan pelaporan yang dituliskan dalam bentuk pendokumentasian asuhan keperawatan yang secara keseluruhan setiap tahapannya dikenal dengan tahapan proses keperawatan. Disisi lain pendokumentasian asuhan keperawatan merupakan bukti fisik aktivitas atau kinerja perawat dalam bentuk data administrasi yang mutlak harus ada karena memiliki banyak manfaat. Salah satu manfaat dari pendokumentasian asuhan keperawatan adalah menunjukan profesionalisme perawat di tatanan pelayanan klinis. Menurut Potter dan Perry (2005), dokumentasi merupakan segala sesuatu yang tertulis atau tercetak yang dapat diandalkan sebagai catatan tentang bukti individu. Dokumentasi yang baik mencerminkan kwalitas perawatan dan yang membuktikan mempertanggunggugatan setiap anggota tim perawatan dalam memberikan asuhan keperawatan pada klien. Sistem dokumentasi yang ideal harus memberikan informasi klien yang komprehensif, dokumen legal.

Pendokumentasian yang baik dimulai dari pengkajian, diagnosa keperawatan, perencanaan, implementasi dan evaluasi yang ditulis dengan lengkap. Akan tetapi fenomena yang terjadi dilapangan, masih banyak tenaga perawat yang belum mendokumentasikan asuhan keperawatan dengan baik sekalipun tingkat pendidikan dan kompetensinya cukup mendukung untuk melakukan pendokumentasian asuhan keperawatan dengan baik.Beberapa hal yang sering menjadi alasan antara lain banyak kegiatan-kegiatan di luar tanggung jawab perawat menjadi beban dan harus dikerjakan oleh tim keperawatan, sistem pencatatan yang diajarkan terlalu sulit dan banyak menyita waktu, tidak semua tenaga perawat yang ada di institusi pelayanan memiliki pengetahuan dan kemampuan yang sama untuk membuat dokumentasi keperawatan sesuai standar yang ditetapkan dan dikembangkan oleh tim pendidikan keperawatan sehingga mereka tidak mau membuatnya (Arikh, 2011). 


\section{PEMBAHASAN}

Keperawatan di Indonesia saat ini masih dalam suatu proses profesionalisasi, yaitu terjadinya suatu perubahan dan perkembangan karakteristik sesuai tuntutan secara global dan lokal. Untuk mewujudkannya maka perawat harus mampu memberikan asuhan keperawatan secara profesional kepada klien. Salah satu bukti asuhan keperawatan yang profesional tercermin dalam pendokumentasian proses keperawatan. Dokumentasi keperawatan adalah bagian dari keseluruhan tanggung jawab perawatan pasien. Catatan klinis memfasilitasi pemberian perawatan, meningkatkan kontinuitas perawatan dan membantu mengkoordinasikan pengobatan dan evaluasi pasien (Iyer, 2004). Responsibilitas dan akuntabilitas profesional merupakan salah satu alasan penting dalam pendokumentasian asuhan keperawatan yang akurat (Iyer, 2004). Dokumentasi keperawatan sangat penting bagi perawat dalam memberikan asuhan keperawatan karena pelayanan keperawatan yang diberikan kepada klien membutuhkan catatan dan pelaporan yang dapat digunakan sebagai tanggung jawab dan tanggung gugat dari berbagai kemungkinan masalah yang dialami klien baik masalah kepuasan maupun ketidakpuasan terhadap pelayanan yang diberikan (Hidayat, 2001).

Penyelenggaraan proses keperawatan terdiri dari pengkajian, diagnosa, perencanaan, implementasi dan evaluasi. Semua tindakan tersebut harus didokumentasikan sebagai bukti penyelenggaraan proses keperawatan. Data klinis yang lengkap dan berkualitas dapat meningkatkan mutu layanan kesehatan. Keengganan klinisi menulis secara lengkap setiap proses penatalaksanaan medis merupakan kendala yang dihadapi.Dokumentasi keperawatan terdiri dari 1) keterampilan berkomunikasi untuk pengumpulan data dan menciptakan hubungan baik antara perawat dan klien dalam pemecahan masalah klien.

2) dokumentasi proses keperawatan yang merupakan metode pemecahan masalah secara sistimatis sesuai kaidah keperawatan dan

3) standar dokumentasi dapat memberi informasi pernyataan kualitas dan kuantitas dokumentasi untuk memperkuat pola pendokumentasian keperawatan

Pendokumentasian merupakan unsur pokok dalam tugas dan tanggung jawab hukum setelah melakukan tindakan keperawatan kepada pasien. Pendokumentasian yang baik mempunyai ciriciri berdasarkan fakta, data yang akurat, kelengkapan, ringkas, terorganisasi, ketepatan waktu, 
mudah untuk dibaca. Dokumentasi asuhan keperawatan yang berkualitas harus terdapat unsur keakuratan, kelengkapan, dan kerelevananan. Kegiatan dokumentasi keperawatan yang tidak lengkap dalam pendokumentasian, keakuratan dan tidak relevan maka akan terjadi kesulitan dalam melakukan pembuktian tindakan yang sudah dilaksanakan dengan baik dan benar.

Keberhasilan pendokumentasian asuhan keperawatan sangat dipengaruhi oleh seorang perawat sebagai ujung tombak dalam memberikan asuhan keperawatan. Menurut Gibson (1996) dalam Suratun (2008) bahwa faktor individu yang memengaruhi perilaku kerja antara lain umur, lama kerja, pendidikan, dan pelatihan. Produktivitas seorang pekerja menurun dengan bertambahnya umur, sedangkan lama kerja mempunyai hubungan yang positif terhadap produktivitas pekerjaan. Siagian (2002) menyatakan bahwa makin tinggi tingkat pendidikan seseorang makin besar keinginan untuk memanfaatkan pengetahuan dan keterampilan.

Dalam membuat dokumentasi harus memperhatikan aspek-aspek keakuratan data, breafity (ringkas), dan legality (mudah dibaca). Adapun prisip-prinsip dalam melakukan dokumentasi yaitu:

a. Dokumen merupakan suatu bagian integral dari pemberian asuhan keperawatan.

b. Praktik dokumentasi bersifat konsisten.

c. Tersedianya format dalam praktik dokumentasi.

d. Dokumentasi hanya dibuat oleh orang yang melakukan tindakan atau mengobservasi langsung klien.

e. Dokumentasi harus dibuat sesegera mungkin.

f. Catatan harus dibuat secara kronologis.

g. Penulisan singkatan harus menggunakan istilah yang sudah berlaku umum dan seragam.

h. Tuliskan tanggal, jam, tanda tangan, dan inisial penulis.

i. Catatan harus akurat, benar, komplit, jelas, ringkas, dapat dibaca, dan ditulis dengan tinta.

j. Dokumentasi adalah rahasia dan harus disimpan dengan benar

\section{A. Tujuan Dokumentasi Keperawatan}

1. Komunikasi: catatan berfungsi sebagai sarana komunikasi bagi berbagai professional kesehatan yang berinteraksi dengan klien. Hal ini mencegah keterlambatan perawatan klien. 
2. Merencanakan asuhan klien: setiap profesional menggunakan data dari catatan klien untuk merencanakan asuhan bagi klien tersebut.

3. Mengaudit institusi kesehatan: audit adalah tinjauan catatan klien untuk tujuan jaminan mutu. Untuk menentukan apakah institusi kesehatan tersebut memenuhi standar yang ditetapkan.

4. Penelitian: informasi yang tercantum dalam catatan dapat menjadi sumber data yang berharga untuk penelitian. Rencana terapi untuk sejumlah klien dengan masalah kesehatan yang sama dapat memberikan informasi yang bermanfaat dalam menangani klien lain.

5. Pendidikan: mahasiswa dalam disiplin kesehatan seringkali menggunakan catatan klien sebagai instrument pembelajaran. Catatan seringkali dapat memberikan pandangan komprehensif tentang klien, penyakit, strategi pengobatan yang efektif dan faktor yang mempengaruhi penyakit.

6. Penggantian pembayaran: dokumentasi juga membantu fasilitas menerima penggantian pembayaran dari pemerintah atau asuransi.

7. Dokumentasi sah: catatan klien adalah dokumentasi sah dan biasanya dapat diterima di pengadilan sebagai bukti.

8. Analisis layanan kesehatan: informasi dari catatan dapat membantu pembuat rencana perawatan kesehatan untukmeng identifikasi kebutuhan institusi. Catatan dapat digunakan untuk menetapkan biaya berbagai layanan dan mengidentifikasi layanan yang menghabiskan dana institusi dan layanan yang menghasilkan pendapatan.

\section{B. Manfaat dan Pentingnya Dokumentasi Keperawatan}

\section{Hukum}

Semua catatan informasi tentang klien merupakan dokumentasi resmi dan bernilai hukum. Bila terjadi suatu masalah (misconduct) yang berhubungan dengan profesi keperawatan, dimana perawat sebagai pemberi jasa dan klien sebagai pengguna jasa, maka dokumentasi dapat dipergunakan sewaktu-waktu. Dokumentasi tersebut dapat dipergunakan sebagai barang bukti di 
pengadilan. Oleh karena itu, data-data harus diidentifikasi secara lengkap, jelas, objektif, dan ditandatangani oleh tenaga kesehatan (perawat), diberi tanggal, dan perlu dihindari adanya penulisan yang dapat menimbulkan interpretasi yang salah.

\section{Kualitas Pelayanan}

Pendokumentasian data klien yang lengkap dan akurat akan memberi kemudahan bagi perawat dalam membantu menyelesaikan masalah klien. Untuk mengetahui sejauh mana masalah klien dapat teratasi dan seberapa jauh masalah dapat diidentifikasi dan dimonitor melalui dokumentasi yang akurat. Hal ini akan membantu meningkatkan kualitas (mutu) pelayanan keperawatan.

\section{Komunikasi}

Dokumentasi keadaan klien merupakan alat "perekam" terhadap masalah yang berkaitan dengan klien. Perawat atau profesi kesehatan lain dapat melihat dokumentasi yang ada dan sebagai alat komunikasi yang dijadikan pedoman dalam memberikan asuhan keperawatan.

\section{Keuangan}

Dokumentasi dapat bernilai ekonomi, semua asuhan keperawatan yang belum, sedang, dan telah diberikan dan didokumentasikan dengan lengkap dapat dipergunakan sebagai acuan atau pertimbangan dalam perhitungan biaya keperawatan bagi klien.

\section{Pendidikan}

Dokumentasi mempunyai nilai pendidikan, karena dokumentasi menyangkut kronologis dari kegiatan asuhan keperawatan yang dapat dipergunakan sebagai bahan atau referensi pembelajaran bagi peserta didik atau profesi keperawatan.

\section{Penelitian}

Dokumentasi keperawatan mempunyai nilai penelitian. Data yang terdapat didalamnya mengandung informasi yang dapat dijadikan sebagai bahan atau objek riset dan pengembangan profesi keperawatan. 


\section{Akreditasi}

Melalui dokumentasi keperawatan akan dapat dilihat sejauh mana peran dan fungsi perawat dalam memberikan asuhan keperawatan kepada klien. Dengan demikian dapat diambil kesimpulan mengenai tingkat keberhasilan pemberian asuhan keperawatan yang diberikan guna pembinaan dan pengembangan tingkat lanjut. Hal ini selain bermanfaat bagi peningkatan mutu

kualitas pelayanan juga bagi individu perawat dalam mencapai tingkat kepangkatan yang lebih tinggi.

\section{PENUTUP}

Dokumentasi asuhan keperawatan adalah suatu catatan yang memuat seluruh data yang dibutuhkan untuk menentukan diagnosis keperawatan, perencanaan keperawatan, tindakan keperawatan, dan penilaian keperawatan yang disusun secara sistematis, valid, dan dapat dipertanggungjawabkan secara moral dan hukum

Pelaksanaan dokumentasi keperawatan merupakan salah satu alat ukur untuk mengetahui, memantau, dan menilai suatu pelayanan asuhan keperawatan yang dilakukan oleh rumah sakit (Fischbach, 1991). Dokumentasi keperawatan tidak hanya mencerminkan kualitas perawatan saja tetapi membuktikan pertanggunggugatan setiap tim keperawatan (Potter \& Perry, 2005). Oleh karena itu, jika kegiatan keperawatan tidak didokumentasikan dengan baik, akurat, obyektif, dan lengkap serta sesuai dengan standar asuhan keperawatan maka sulit untuk membuktikan bahwa tindakan keperawatan telah dilakukan dengan benar. 


\section{DAFTAR PUSTAKA}

Astuti,N.,Yarnita,Y.,\&Mayasari,E.(2010).Analisis Kelengkapan Pendokumentasian Asuhan

Keperawatan PAasien Di Ruang Rawat Inap Rumah Sakit Tampan Pekanbaru. Jurnal Photon, 1(1)

Fatie,M., Felle,Z,R. (2018). HUBUNGAN TINGKAT PENDIDIKAN PERAWAT DENGAN PENERAPAN KOMPETENSI PENDOKUMENTASIAN PROSES KEPERAWATAN. JURNAL KEPERAWATAN TROPIS PAPUA, 1(1) ISSN 2654 - 5756.

Gustomi,M,P.,Churin'in. (2015). PENERAPAN MODEL DOKUMENTASI ASUHAN KEPERAWATAN PROBLEM ORIENTED RECORD (POR) TERHADAP KINERJA PERAWAT (Effect of Problem Oriented Record (POR) Nursing Documentation Model on the Performance of Nurses). Journals of Ners Community, 6(2),150 - 157

Mangole,J,E., Rompas,S.,\&Ismanto,A,Y.(2015). HUBUNGAN PERILAKU PERAWAT DENGAN PENDOKUMENTASIAN ASUHAN KEPERAWATAN DI CARDIOVASKULAR AND BRAIN CENTER RSUP PROF. DR. R. D. KANDOU MANADO. E-journal Keperawatan $(\mathrm{e}-\mathrm{Kp}), 3(2)$

Muryani,Pertiwiwati,E.,\& Setiawan,H.(2019). KUALITAS PENDOKUMENTASIAN ASUHAN KEPERAWATAN DI RUANG RAWAT INAP (Studi di RSUD Kalimantan Tengah). Nerspedia, 2(1),27-32

Noorkasiani, Gustina,R,\& Maryam,S.(2015). FAKTOR-FAKTOR YANG BERHUBUNGAN DENGAN KELENGKAPAN DOKUMENTASI KEPERAWATAN. Jurnal Keperawatan Indonesia, 18(1), 1-8

Olfah, Y., Ghofur A. (2016). Dokumentasi Keperawatan.Pusdik SDM Kesehatan Badan Pengembangan dan Pemberdayaan Sumber Daya Manusia Kesehatan. Kebayoran Baru,Jaksel

Rosmalia,D., Machmud,R.,\& Mangkuto,H.(2014). Analisis Sistim Manajemen Dokumentasi Keperawatan pada Poliklinik Gigi Rumah Sakit di Bukittinggi, Jurnal Kesehatan Andalas. 3(1)

Simamora, R. (2009). Dokumentasi Proses Keperawatan. 
Simamora, R. H., Purba, J. M., Bukit, E. K., \& Nurbaiti, N. (2019). Penguatan Peran

Perawat Dalam Pelaksanaan Asuhan Keperawatan Melalui Pelatihan Layanan Prima. JPPM (Jurnal Pengabdian Dan Pemberdayaan Masyarakat), 3(1), 25-31.

Sugiyati,S.(2015). HUBUNGAN PENGETAHUAN PERAWAT DALAM DOKUMENTASI KEPERAWATAN DENGAN PELAKSANAANNYA DI RAWAT INAP RSI KENDAL. Jurnal keperawatan FIKKES, 8 (2), 109 - 125

Tarigan,R., Handiyani,H. (2019). Manfaat Implementasi Dokumentasi Asuhan Keperawatan

Berbasis Komputerisasi Dalam Meningkatkan Mutu Asuhan Keperawatan. Jurnal Ilmiah Kesehatan Pencerah, 08 (2), 110-116 